\title{
A Novel Electric Power Plants Performance Assessment Technique Based on Genetic Programming Approach
}

\author{
Ahmad Attari Ghomi ${ }^{1}$, Ayyub Ansarinejad ${ }^{2}$, Hamid Razaghi ${ }^{1}$, Davood Hafezi ${ }^{1}$ \& Morteza Barazande ${ }^{1}$ \\ ${ }^{1}$ Qom Province Electricity Distribution Company, Qom, Iran \\ ${ }^{2}$ Department of Industrial Engineering, University of Tehran, Tehran, Iran \\ Correspondence: Ayyub Ansarinejad, Department of Industrial Engineering, University of Tehran, Tehran, Iran. \\ E-mail: ansarinejad@outlook.com
}

Received: January 26, 2014

Accepted: March 13, 2014

Online Published: April 8, 2014

doi:10.5539/mas.v8n3p43

URL: http://dx.doi.org/10.5539/mas.v8n3p43

\begin{abstract}
This paper presents a novel nonparametric efficiency analysis technique based on the Genetic Programming (GP) in order to measure efficiency of Iran electric power plants. GP model was used to predict the output of power plants with respect to input data. The method, we presented here, is capable of finding a best performance among power plant based on the set of input data, GP predicted results and real outputs. The advantage of using GP over traditional statistical methods is that in prediction with GP, the researcher doesn't need to assume the data characteristic of the dependent variable or output and the independent variable or input. In this proposed methodology to calculate the efficiency scores, a novel algorithm was introduced which worked on the basis of predicted and real output values. To validate our model, the results of proposed algorithm for calculating efficiency rank of power plants were compared to traditional method. Real data was presented for illustrative our proposed methodology. Results showed that by utilizing the capability of input-output pattern recognition of GP, this method provides more realistic results and outperform in identification of efficient units than the conventional methods.
\end{abstract}

Keywords: electric power plants, performance evaluation, genetic programming

\section{Introduction and Background}

The most significant issues developing countries are facing with, is finding the appropriate way of operating and managing their power industries (Yunos \& Hawdon, 1997). Electricity is extremely important in the economic development of every society (Liu et al., 2010). In 2007, Iran generated about 190 billion kilowatt-hours (Bkwh) electricity and consumed $153 \mathrm{Bkwh}$. Iran heavily relies on conventional fossil fuel power plants (especially natural gas generator). Iran's nominal electrical production capacity is about 49,000 Megawatts (MW). Nominal capacity of some power plants is under $10 \%$. Most power plants in Iran are old, and can't work under nominal capacity. On the other hand, Iran needs to increase its power plants generate capacity around $10 \%$ annually, to fulfill the 7-9 percent annual demand growth (http://www.eia.doe.gov).

The expenses of constructing electricity power plants and producing electricity are relatively high. In addition, the environmental damage and its consequent costs of burning fossil fuels for electricity generation is remarkable. Hence, performance assessment and efficiency evaluation of a group of selected homogenous thermal electricity power plants or in performance evaluation literature, decision-making units (DMUs) to reduce such costs seem necessary. In 2007, 25.6 percent of the whole amount of electricity produced came from gas turbines; 2.2 from hydroelectric plants; 45.4 from steam power plants; and 26.6 from combined cycle power plants. The rest of it was produced by diesel generators. Figure 1 shows the electricity generated by each of different types of power plants in Iran (http://www.tavanir.org.ir). 


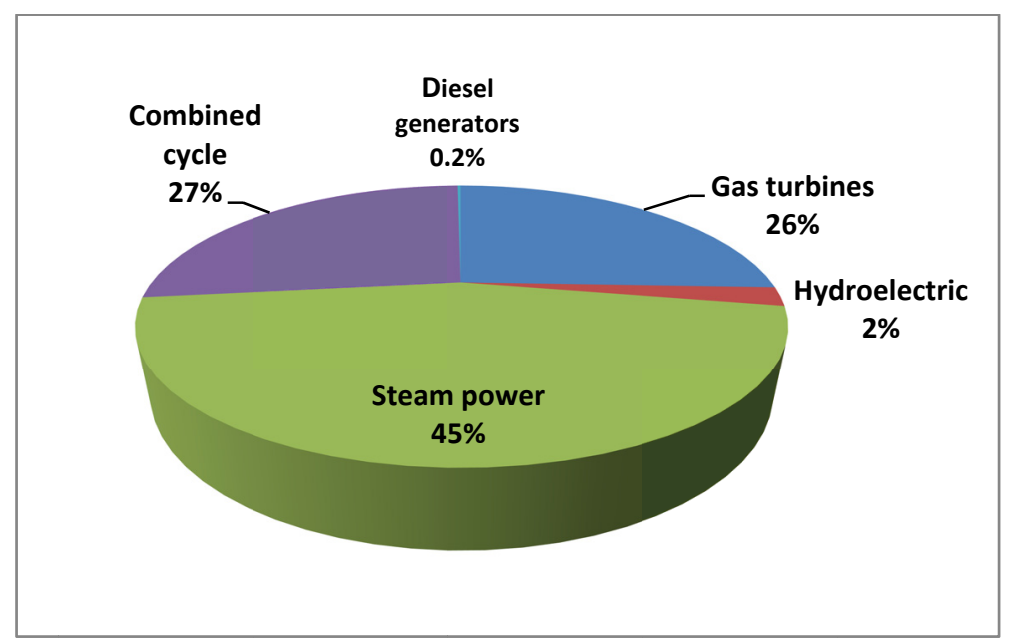

Figure 1. Electricity generation by different types of power plants

One of the benchmarking methods in performance evaluation is frontier benchmarking method. This method has a stronger concentration on performance differences among DMUs than other methods. This approach can be most suitable when the main goal is to reduce the performance space among the DMUs (Jamasb \& Pollitt, 2004). In the field of efficiency frontier analysis, several approaches and methodologies are applied in the past thirty years, like performance indicators. There are different types of parametric econometric methods such as ordinary least square (OLS), Stochastic frontier approach (SFA), thick frontier approach (TFA) and distribution-free approach (DFA). Data Envelopment Analysis (DEA) and Free Disposal Hull are two widely used and well known nonparametric methods which are based on a mathematical programming (Tyagi et al., 2009; Bauer et al., 1998). These parametric and non-parametric methodologies are applied to many cases in electrical field (Azadeh et al., 2009; Iglesias et al., 2010; Park \& Lesourd, 2000; Yunos \& Hawdon, 1997; Pérez-Reyes \& Tovar, 2010; Sueyoshi et al., 2010). Among the efficiency frontier analyses, DEA is more widely applied in many fields. Park and Lesourd (2000) presented an application of DEA-BCC (Banker, Charnes and Cooper) and SFA for measuring of South Korea, 64 conventional fuel power plants efficiencies. To improve the statistical explanation of data, they export the DEA-BCC efficiency results into an econometric estimate of a standard production function. They further perform a statistical analysis of the DEA results and compared the results with results obtained by the previous stochastic-frontier method (Park \& Lesourd, 2000). During the period 2001-2004, Iglesias et al. (2010) applied DEA and SFA methods, to measure the relative efficiency of a set of wind farms. They debated that the results can provide, an important pre efficiency measure, plus economic impact aspects of relevance for wind farm development companies (developers), technology suppliers and operators (Iglesias et al., 2010). During 2004-2006, Liu et al. (2010) evaluate the power-generation efficiency of main thermal power plants in Taiwan using DEA. In the mentioned study to verify the stability of the DEA model a stability test was performed. The results show that all power plants achieved acceptable overall operational efficiencies. Combined cycle power plants were the most efficient plants (Liu et al., 2010).

Pombo and Taborda (2006) assessed Colombia's power distribution utilities performance before and after the regulatory reform in 1994. They measured the DEA technical efficiencies and showed that econometric tests on DEA efficiency scores show a positive effect of regulatory reform. Sueyoshi and Goto (2001) applied the slack-adjusted DEA (SA-DEA) model to examine the performance of Japanese electric power generation companies from 1984 to 1993. It is clear that by applying different methods and considering the variety of assumptions in different methods, Inconsistency of conclusions for DMUs efficiency are often happened (Azadeh et al., 2010). Each of the parametric and non-parametric methods has its strengths and weaknesses. The parametric methods require assumption about the data characteristic structure. Despite the fact that the non-parametric methods do not require any assumption for data structure, therefore if the data has statistical noise the calculated efficiencies, e.g. by DEA, may be distorted (Tyagi et al., 2009; Bauer, 1990). Azadeh et al. (2007) mentioned the fact that DEA is barely capable to estimate the DMUs performance. They showed that artificial neural networks (ANNs) can be used to overcome this issue. ANNs are the widely accepted pattern recognition approach. The ANN mechanism is motivated by the animal central nervous systems. It has been proven that ANNs are efficient in estimating the production function behavior and then in measuring the efficiency considering non linear condition (Azadeh et al., 2007). Despite having a very good performance, 
ANNs is not capable of extracting interpolation equations. The ANN implementation is needed to be done by a computer program. The new hybrid approach combining DEA and ANNs (Athanassopoulos \& Curram, 1996) has been applied in many fields (Mostafa, 2009; Pendharka, 2010; Çelebi \& Bayraktar, 2008; Wu, 2009; Wu et al., 2006; Wang et al., 2009). Wu et al. (2006) integrated DEA and ANNs to calculate the relative efficiency of a big Canadian bank branches. In this study in first stage a CCR model of DEA and in the next stage NN model was used to measure the relative efficiencies. By better estimation of performance pattern this approach can identify efficient units robustly. In the field of vendor evaluation and selection, Wu (2009) presented a DEA, decision trees and NNs hybrid model to evaluate performance of suppliers. The mentioned hybrid model can perform as a classification and a regression model simultaneously. The model consists of two modules: Module 1 calculate DEA efficiencies and Module 2 utilizes efficiencies data to train Decision Tree, NNs model and applies the DT-NN model to new suppliers. In this paper Genetic programming (GP) is applied as a novel approach for evaluating performance of power generation industry. GP is a machine learning method that can be used to find the best fitness function. The results of GP are represented as hierarchy structures and show the steps to obtain the fitness function. The main advantage of GP over ANN and traditional statistical methods is its ability to generate simplified estimation equations without considering any assumption about data relationship and structure of data. GP is applied in several fields (Kaboudan, 2003) such as forecasting electricity demand (Lee et al., 1997); forecasting long term energy consumption (Karabulut et al., 2008) in real-time runoff (Khu et al., 2001); predicting financial data (Iba \& Sasaki, 2002); predicting stock prices (Kaboudan, 2000) in fault analysis of the diesel engine fuel (Sun et al., 2004); prediction of ski-jump bucket spillway scour (Azamathulla et al., 2008); river pipeline scour (Azamathulla \& Ghani, 2010) and longitudinal dispersion coefficients in streams (Azamathulla \& Ghani, 2011) and etc. This study presents a genetic programming procedure for performance evaluating of a set of homogeneous steam power plants and benchmarking. By considering a set of power plants of same types to apply the presented model, more accurate and reliable results are guaranteed.

\section{Genetic Programming}

Genetic programming (GP) as an extension of the genetic algorithms was firstly presented by Koza (1992). GP is an area of evolutionary computation methods that creates computer programs.

The computer programs generated by GP are presented as tree structures and expressed in the functional programming language (LISP) (Koza, 1992). The classical GP technique is also called "tree-based GP" (Koza, 1992). The main differences between GP and GA are (Willis et al., 1997):

- GP creates solutions or chromosomes as a tree structured in the variable length; while GA's generally make use of chromosomes of fixed length and structure.

- GP typically integrate syntax with a specific domain that regulates meaningful arrangements of information on the chromosome. For GAs, the chromosomes are typically syntax-free.

- GP maintain the syntax of its tree-structured chromosomes in 'reproduction' step, by using the genetic operators.

- GP solutions are often coded in the way that let the chromosomes to be executed directly. GA's are rarely coded in this form.

GP is able to automatically predict the generation of mathematical expressions or programs (Tsakonas, 2006). Like many other areas of computer sciences, GP has been widely utilized in the real world condition. GP creates numerous random populations in the large space of possible solutions (computer programs) to avoid the likelihood of stopping in a "local optimum" (Muttil \& Lee, 2005). The functions or programs are called organisms or chromosomes. During the evolution process to find best solution, the size and form of the populations dynamically change (Brezocnik \& Balic, 2001). From a set of function and terminal genes, possible solutions in GP can be formed in a recursive manner.

In GP, function set (F) is consisting of all mathematical functions (the basic mathematics operations $(+,-, \times, /$, etc.), Boolean logic functions (AND, OR, NOT, etc.) or ...).

The terminal set $\mathrm{T}$ contains the arguments for the functions and can consist of numerical constants, logical constants, variables, etc. In Figure 2 a simple tree structure of a GP model is shown. GP Tree structure has a root node with links went out from each function and end to a terminal. 


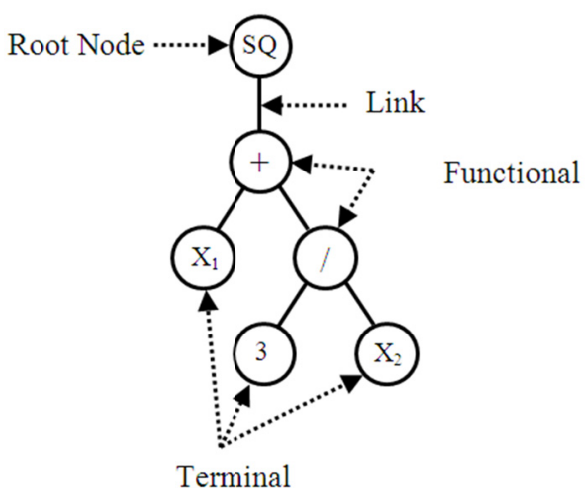

Figure 2. The tree structure of a GP model $\left(\mathrm{X}_{1}+3 / \mathrm{X}_{2}\right)^{2}$ (Gandomi et al., 2010)

After several random populations of random parse trees has been produced, the GP algorithm calculates their fitness and selects the better parse trees for generates new individuals by reproduction, crossover, and mutation, in all iterations, GP creates the new generation (Koza, 1992). This three process (selection, reproduction and variation) will be go on until the specific stopping criterion (such as specific MSE) is satisfied. During the crossover procedure, a point on a branch of each pair of chosen parent is selected randomly and then the set of terminals and/or functions from that point exchanged to obtain two new programs. To ensure the exchange of genetic material among the evolved programs the crossover operation is required. Figure 3 shows a typical crossover operation of two computer programs. From two parental computer programs (Parent I, Parent II) two new child computer programs (Child I, Child II) are generated. The randomly generated Childs by crossover can be seen in Figure 3. Both child programs include the genetic material from their parents. Preserve syntactical structure of the computer programs during the crossover process is very important (Kovacic et al., 2004).
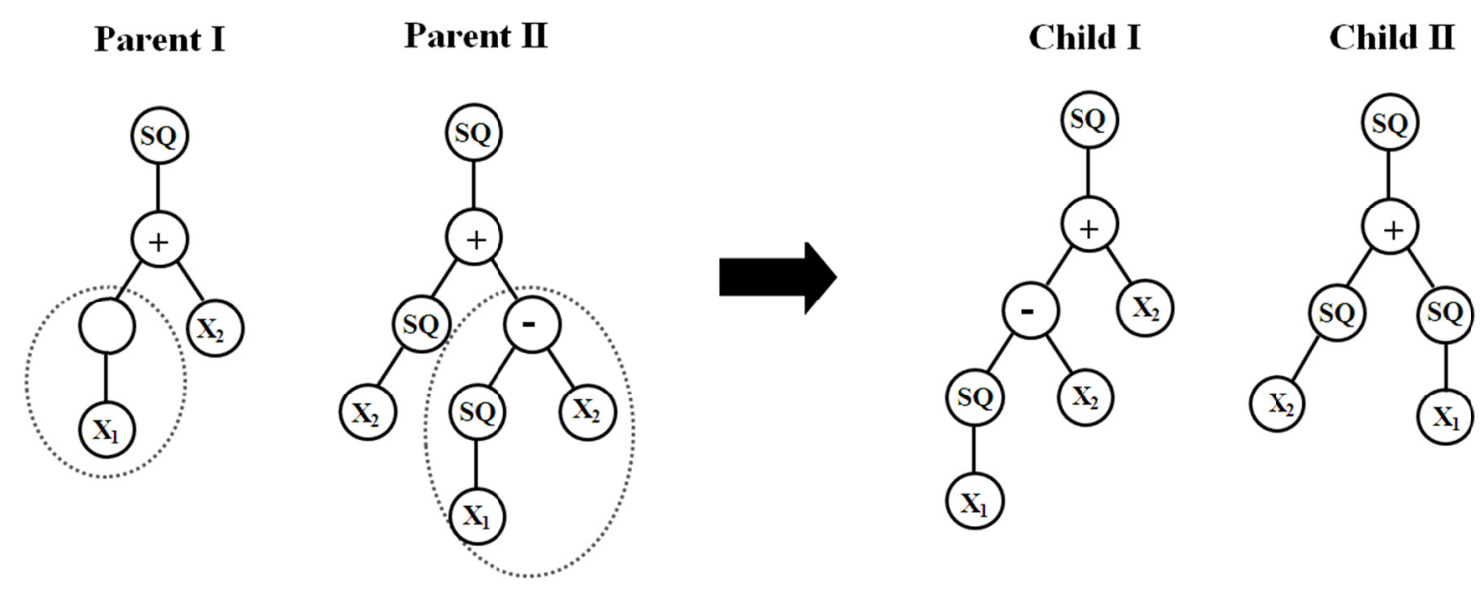

Figure 3. Typical crossover operation in GP (Gandomi et al., 2010)

Crossover is responsible for improvements in fitness, and mutation takes a secondary role responsible for reintroducing random population that have been missed from the population. In the mutation operation, the GP algorithm selects a function or terminal randomly and mutates it. Both of a function node or a terminal node can be exchanged during mutation. A node in the tree is chosen at random. If it's a terminal node it is simply replaced by another terminal and if it is a function node in the point mutation application, it is replaced by a new function with the same equality. In the tree mutation application, a new function node (not necessarily with the same parity) is chosen, and the original node together with its relative sub-tree is substituted by a new randomly generated sub-tree (Li et al., 2007). Figure 4 shows a typical mutation operation in GP. Generally mutation doesn't play a major role in GP (Koza, 1992). 


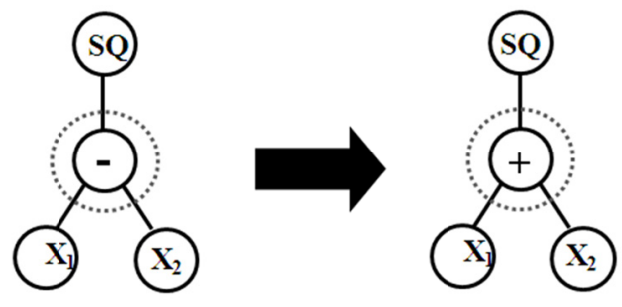

Figure 4. Typical mutation operation in GP

Here are the steps the GP algorithm follows to generate a computer programs (see Figure 5):

(1) Creation an initial population by producing of random compositions of the functions and terminals (computer programs).

(2) Execution of the programs in the population separately and calculate fitness values of each programs to find out how well they solve the problem.

(3) Creation of a new population of programs.

- Copying the best existing programs (reproduction).

- Creating new computer programs by the crossover and mutation operations.

(4) The best program that can be found in any generation defines the output of the GP algorithm (Koza, 1992).

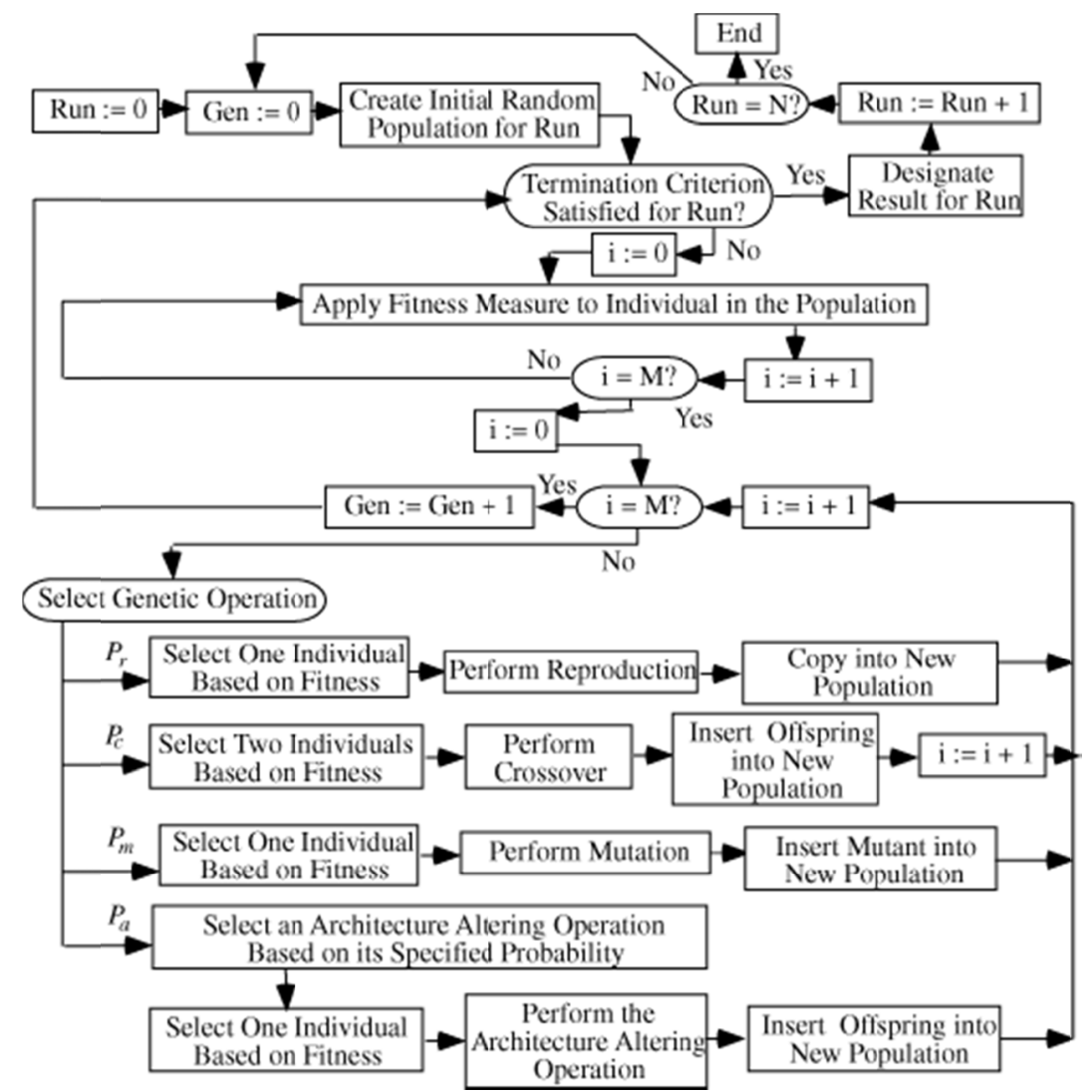

Figure 5. Flowchart of genetic programming (Koza, 1992)

\subsection{Unique Aspects of GP}

The main benefit of GP in over the other artificial intelligence and traditional approaches (such as NN and Regression), is that GP does not need any definition of functional form of solutions to start optimization. GP creates many randomly functions and selects the one with the best fitness value. The benefit of GP over the 
conventional regression methods is that conventional regression need to specify the model structure in advance, which is mostly suboptimal. ANNS require the identification of the network structure and then the coefficients (weights) are calculated during the learning process. In GP, the terminal and function sets are defined initially, and then both the optimal form of the model and the coefficients are calculated by GP algorithm (Muttil \& Lee, 2005). The GP models can provide additional information about the problem by finding the best fit analytic function. In contrast, ANNs can't provide any analytical function besides the interpretation of the network weights is not generally possible. Opposing to ANNS, GP have a good ability to distinguish among the effective input data and inputs that have no effect on a solution. Therefore, GP can reduce the dimension of the model, and better model interpretation will be achieved (Muttil \& Lee, 2005).

\section{Methodology}

In the present study, a GP-based algorithm is introduced to measure Iran's main electricity power plants efficiency during a specific period. The presented model is input oriented because of the selected power plants have particular demand to fulfill. Thus, the input quantities are the main decision parameters. By finding cost function instead of production function the GP method can be extend as an output oriented model. In this study one output is considered for simplicity. The proposed algorithm is as follows:

(1) Divide the data to input (S) and output (P) sets. Assume that "n" power plants have to be assessed.

(2) Form $\mathrm{S}$ as inputs contain all data from input variables of the previous periods.

(3) Divide $\mathrm{S}$ to two sub sets: learning $\left(\mathrm{S}_{\text {Learning }}\right)$ and validation $\left(\mathrm{S}_{\text {validation }}\right)$ sets.

The learning data are used for learning process. A validation data are also used to test the capability of the model on new data. During the learning process the performance of the evolved models on the validation set is monitored.

The learning and validation data sets used to select the best evolved models and included in the training process. Since better extrapolate of GP is preferred the validation data are chosen from closer data periods $\mathrm{S}_{\text {Testing. }}$.

(4) Use GP method to find best program function.

(A) Choose training variables.

(B) Train GP using the learning data $\left(\mathrm{S}_{\text {Learning }}\right)$.

(C) Evaluate the model using the validation data $S_{\text {Validation }}$

Calculate the GP best fit function with the desired precision on the validation data.

(5) Calculate fitness value for $S_{\text {Testing }}$ using the GP best fit function.

(6) Calculate the absolute error between the real output $\left(P_{\text {real }}(i)\right)$ and GP best fit function $\left(P_{G P}(i)\right)$ in the current period:

$$
D_{i}=\left|P_{\text {real }_{(i)}}-P_{G P_{(i)}}\right|, i=1,2, \ldots, n
$$

(7) Calculate the error weight for each predicted value of power plants $\left(E_{\text {weight }_{(i)}}\right)$ :

$$
E_{\text {weight }_{(i)}}=\frac{D_{i}}{\sum_{i=1}^{n} D_{i}}, i=1,2, \ldots, n
$$

(8) Calculate Raw Efficiency Scores: For obtaining Raw Efficiency Scores real value is divided to the summation of effects of the each absolute error ratio $\left(E_{\text {weight }_{(i)}}\right)$ and predicted value.

$$
R E_{\text {score }_{(i)}}=\frac{P_{\text {real }_{(i)}}}{P_{G P_{(i)}}+E_{\text {weight }_{(i)}}}, i=1,2, \ldots, n
$$

(9) Final efficiency scores calculation. The efficiency scores are between 0 and 1 . The power pant with maximum score takes the highest rank.

$$
E_{\text {score }_{(i)}}=\frac{\operatorname{RE}_{\text {score }_{(i)}}}{\operatorname{Max}\left(R_{\text {score }_{(i)}}\right)} \times 100, i=1,2, \ldots, n
$$

The steps of proposed algorithm are illustrated in Figure 6. 


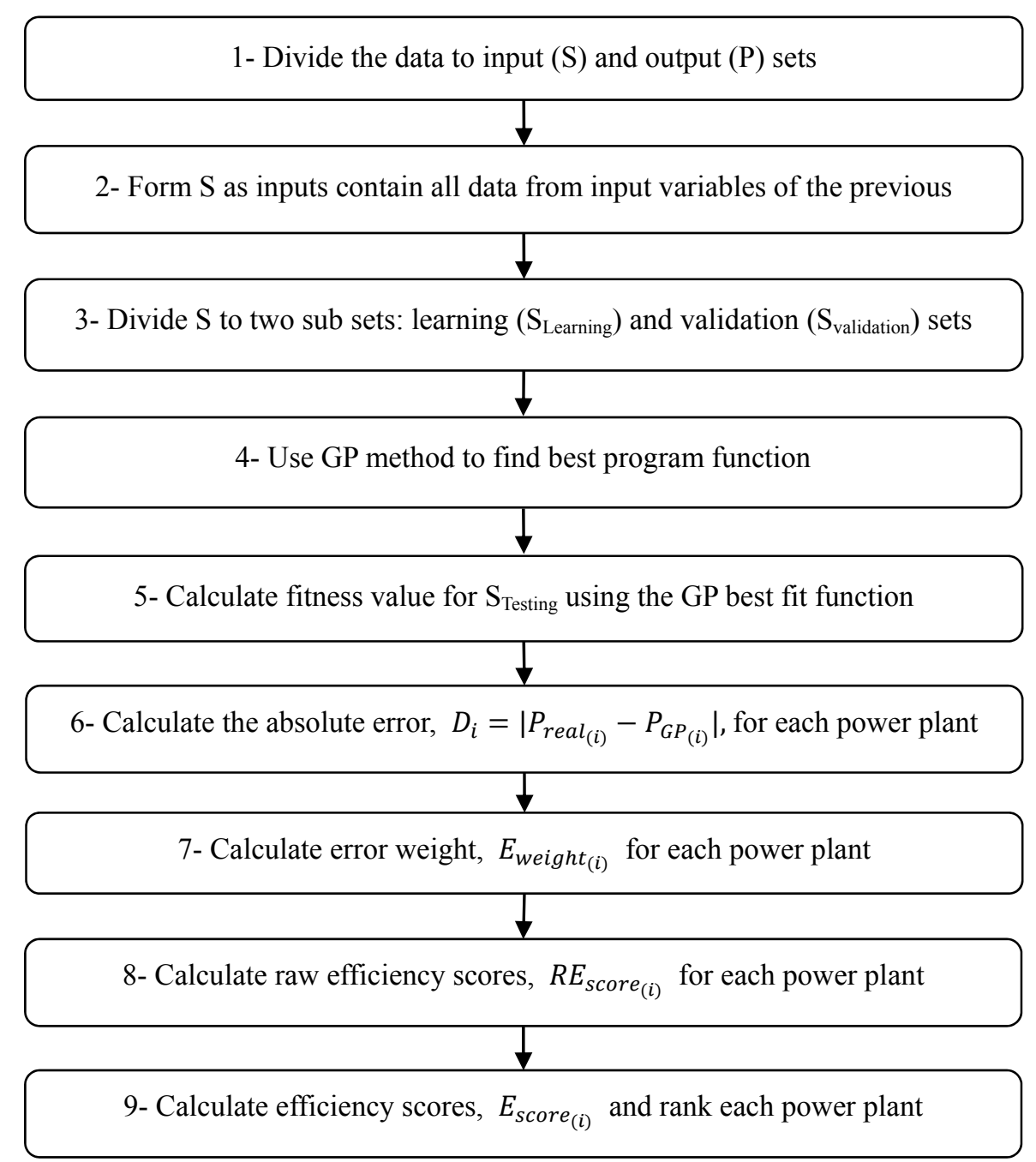

Figure 6. Steps of proposed methodology

\section{Case Study}

The conventional thermal steam-electric production plan is defined by engineering framework. In such framework, appropriate input parameters are the consumed fuel quantity and installed power. The installed power is the maximum nominal power for that the plants are originally designed. Labor input variables are for controlling and maintenance services, which also require funds (Azadeh et al., 2007). Electrical energy production is the output. According to some researches on the performance evaluation of Iran's thermal power plants (e.g., Emami Meibodi, 1998), labor is not a major factor. Consequently, GP-based formulation of the electric power $(\mathrm{MWh})$ generated from thermal power plants in each power plants $(\mathrm{P})$ is considered to be as follows:

$$
P=f(I C, I P, F C)
$$

Where,

IC (MW): Capital (install capacity)

IP (MWh): Internal power (Internal consumption)

FC (TJ): Fuel consumption

IC is measured in terms of installed thermal generating capacity (Hawdon, 1997; Fare et al., 1983). IP is the energy consumption of plant (e.g. powered equipments, etc.). Various fossil fuels such as natural gas, gasoline and mazut have been used as fuel in the production procedure. The type of fuel is depended on availability; cost and environmental issues (Azadeh et al., 2010). FC measurement scale is Tera Joule (TJ). One hundred forty-eight data sets collected from 1997 to 2004 by Azadeh et al. (2010) were used for applying the proposed 
performance evaluation and estimation model. The basic descriptive statistics of model parameters is calculated in Table 1. For more detailed information about Iran's thermal power plants, such as total output, generation capacity and fuel consumption can be found in TAVANIR management organization (1997-2004). To start analysis, the main data sets in several periods were separated to training and testing subsets. The training data were used for the learning process and the testing data were employed to evaluate the capability of the model on data sets that were not included in the analysis.

For analysis data sets from 1997 to 2002, 117 sets were used as the training data (100 sets for learning and 17 sets for validation). Also, 31 data sets from 2003 to 2004 were taken for the testing of the models.

Table 1. The basic descriptive statistics of model parameters

\begin{tabular}{lcccc}
\hline Parameter & IC $(\mathrm{MW})$ & IP $(\mathrm{MWh})$ & FC $(\mathrm{TJ})$ & $\mathrm{P}(\mathrm{MWh})$ \\
\hline Mean & 731.4 & 273767.8142 & 1084398.382 & 4148901.203 \\
Standard Deviation & 557.4 & 200881.381 & 832885.7401 & 3282302.083 \\
Sample Variance & 310687.2 & $4.0 \mathrm{E}+10$ & $6.9 \mathrm{E}+11$ & $1.1 \mathrm{E}+13$ \\
Minimum & 50 & 3215 & 22023 & 56254 \\
Maximum & 1890 & 823033 & 3298201 & 11640505 \\
Confidence Level (95.0\%) & 90.5 & 32632.3 & 135298.4 & 533194.8 \\
\hline
\end{tabular}

In the computerized GP predictive algorithm several parameters should be considered. These parameters should be set properly in order to get the best GP prediction model for the Electricity production in steam power plants. Table 2 shows the GP model parameters. Four basic mathematics operators were sets in the procedure in order to maintain the simplicity of the model. Population size sets the number of programs in the population that GP will evolve. The generation number sets the number of levels the algorithm will use before the run terminates. Based on the complexity of model the appropriate values of these parameters should be selected. Herein, a reasonably large value of initial population and generations were tested to find production function with minimum inaccuracy. The rates of the mutation and crossover operations for the optimal models were $50 \%$. The maximum tree depth was also set to an optimal value of 12 .

The other values of effective parameters are selected based on trial and error experiments (Gandomi et al., 2010). In this study tree-based GP software, GPLAB (Silva, 2007) in addition with subroutines coded in MATLAB was used.

Table 2. The GP parameter settings

\begin{tabular}{ll}
\hline Parameter & Settings \\
\hline Function set &,,$+- \times, /$ \\
Population size & $100-1000$ \\
Maximum tree depth & 12 \\
Total generations & 4000 \\
Initial population & Ramped half-and-half \\
Sampling & Tournament \\
Expected no. of offspring method & Rank 89 \\
Fitness function error type & linear error function \\
Termination & Generation 40 \\
Minimum probability of crossover & 0.1 \\
Minimum probability of mutation & 0.1 \\
Real max level & 30 \\
Survival mechanism & Keep best \\
\hline
\end{tabular}




\subsection{Performance Measures}

Correlation coefficient (R) and mean absolute percent error (MAPE) were used to evaluate the performance of the GP models. R and MAPE are calculated using the following relations:

$$
\begin{gathered}
R=\frac{\sum_{i=1}^{n}\left(h_{i}-\bar{h}_{i}\right)\left(t_{i}-\bar{t}_{i}\right)}{\sqrt{\sum_{i=1}^{n}\left(h_{i}-\bar{h}_{i}\right)^{2} \sum_{i=1}^{n}\left(t_{i}-\bar{t}_{i}\right)^{2}}} \\
M A P E=\frac{1}{n} \sum_{i=1}^{n}\left|\frac{h_{i}-t_{i}}{h_{i}}\right| \times 100
\end{gathered}
$$

where $h_{i}$ and $t_{i}$ are respectively the actual and predicted output values for the $i^{\text {th }}$ output, $\bar{h}_{i}$ is the average of the actual outputs, and $n$ is the number of sample.

\subsection{GP-Based Formulation of Electricity Production and Analysis}

The GP-based formulation of the electric power generated from thermal power plants $(\mathrm{P})$ is as given below:

$$
P(\text { мWh })=\left(\mathrm{IP}+3 \mathrm{FC}-\frac{(9+\mathrm{IC})\left(\mathrm{IC}(\mathrm{FC}-\mathrm{IC})+1377 \mathrm{IC}^{2}\right)}{\mathrm{IP}-\mathrm{IC}-\mathrm{FC}-\mathrm{IC}^{2}}\right)
$$

Comparisons of the measured versus predicted P values using GP are shown in Figure 7. As it is seen, the prediction accuracy of the GP model is very good for both of the training and testing data sets. The contribution of each input parameter in the model was evaluated through a sensitivity analysis. For this purpose, frequency values of the variables were obtained. A frequency value equal to 1.00 for an input indicates that this variable was appeared in $100 \%$ of the best thirty programs evolved by GP. This methodology is a common approach for the GP-based sensitivity analysis (Alavi et al., 2010). The frequency values of the variables are shown in Figure 8 . As can be seen in this figure, the electricity production significantly influenced by all the parameters. However, the results indicate that it is more sensitive to the fuel consumption (FC) and install capacity (IC) than the internal consumption (IP).
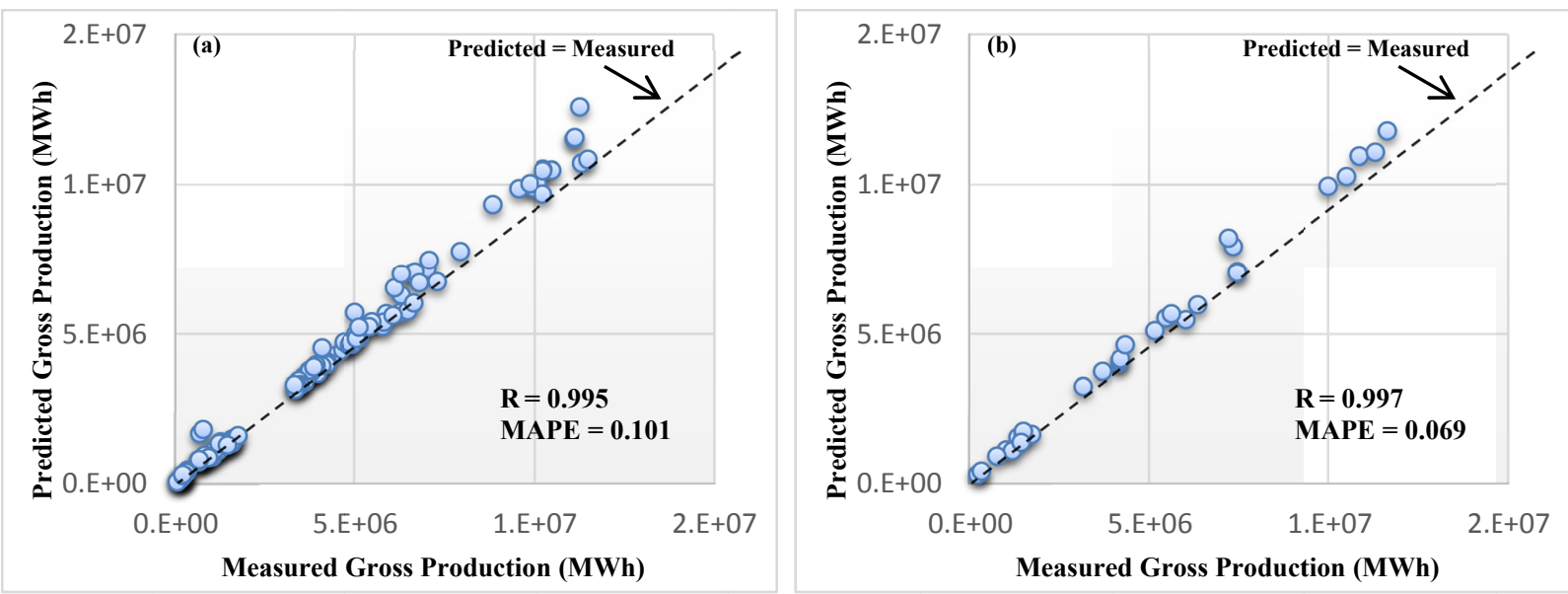

Figure 7. Measured versus predicted electricity production using GP: (a) training data, (b) testing data

To further verification of the model, a parametric study was performed in this study. The main goal is to find the effect of each parameter on the electricity production. The methodology is based on the change of one predictor variable at a time while the other predictor variables are kept constant at the average values of their entire data sets. Figure 9 presents the predicted values of the electricity production as a function of IC, FC, and IP. The results of parametric analysis indicate that the electricity production continuously increases due to increasing IC and IP.As shown in Figure 9(c), the electricity production initially decreases with increasing FC up to about $5.4 \mathrm{E}+05 \mathrm{TJ}$, and afterwards it starts increasing. 


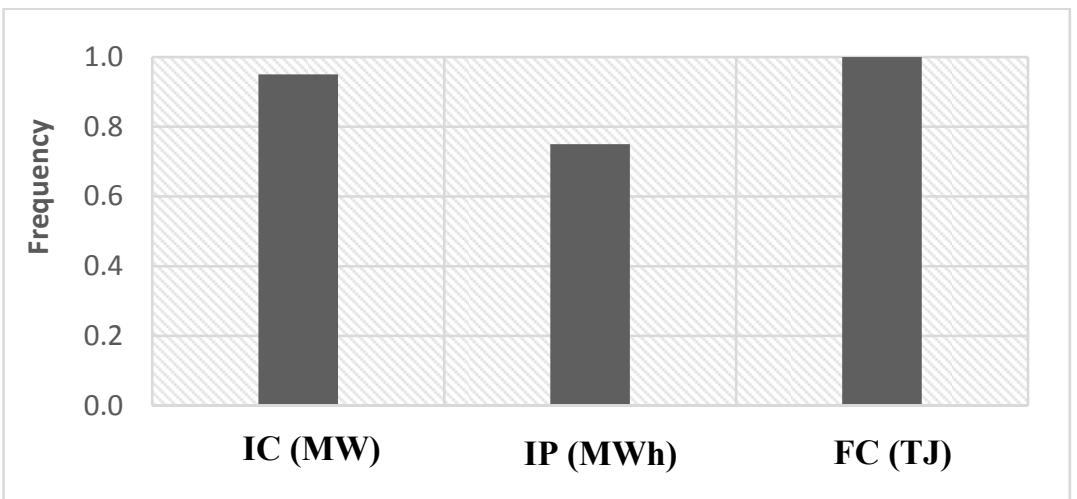

Figure 8 . Sensitivity analysis of the predictor variables in the GP model
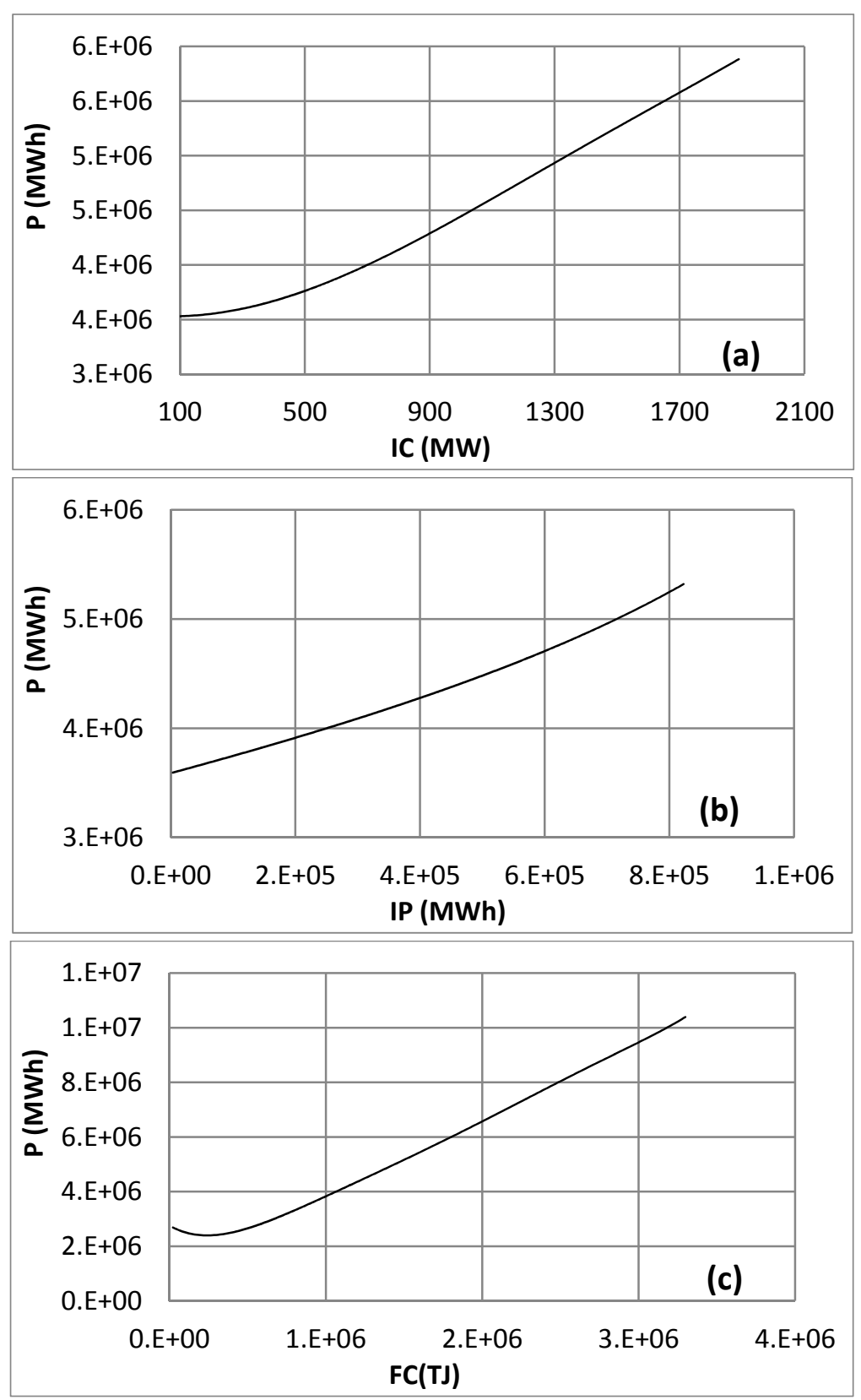

Figure 9. Parametric analysis of the electricity production in the GP model 


\section{Validity Verification}

Based on the estimated results for outputs of power plants calculated by the GP model, the plant efficiencies are quantified. The results are shown in Table 3 through Table 5. In Table 3 the rankings of the power plants based on Athanassopoulos and Curram (1996) study which is called "standardized efficiency" is shown (Costa \& Markellos, 1997; Delgado, 2005; Azadeh et al., 2007). Also Table 4 shows the calculation results according to Azadeh et al. (2007) approach. Finally Table 5 summarized the main results of efficiency scores based on the proposed GP estimation model, which can be seen in Figure 6 .

Table 3. Efficiency scores estimation by the standardized efficiency algorithm

\begin{tabular}{cccccc}
\hline Power Plants & $P_{\text {Real }(i)}$ & $P_{G P(i)}$ & $E i=P_{\text {Real }(i)}-P_{G P(i)}$ & $F i=100 \times\left(P_{\text {Real }(i)} /\left(P_{A N N(i)}+\max E_{i} \mid E_{i} \geq 0\right)\right)$ & Rank \\
\hline Montazerghaem & 3297100 & 3335966.289 & -38866.289 & 89.21 & 10 \\
Besat & 1500253 & 1682872.54 & -182619.536 & 73.45 & 15 \\
Firoozi & 212403 & 310681.88 & -98278.884 & 31.68 & 19 \\
Salimi & 11310817 & 11000250.67 & 310566.328 & 99.57 & 2 \\
Shazand & 7438002 & 7128665.43 & 309336.573 & 99.33 & 3 \\
Rajaei & 6342203 & 5982403.61 & 359799.388 & 100 & 1 \\
Beheshti & 1435991 & 1366089.86 & 69901.139 & 83.2 & 13 \\
Tabriz & 4341330 & 4594212.58 & -252882.575 & 87.63 & 11 \\
Mofatteh & 5134547 & 5314179.90 & -179632.900 & 90.49 & 9 \\
Bistoon & 4210280 & 4095904.47 & 114375.526 & 94.49 & 4 \\
Ramin & 10861867 & 10764449.95 & 97417.052 & 70.72 & 16 \\
Madhaj & 922587 & 944762.00 & -22175.003 & 84.62 & 12 \\
Bandarabbas & 7196540 & 8144942.68 & -948402.683 & 44.47 & 18 \\
Zarand & 341402 & 407945.86 & -66543.857 & 94.32 & 7 \\
Esfahan & 5621431 & 5600168.68 & 21262.323 & 95.66 & 5 \\
Montazeri & 11137177 & 11283224.42 & -146047.415 & 90.96 & 8 \\
Toos & 3831065 & 3851999.95 & -20934.945 & 58.94 & 76.52 \\
Mashhad & 665887 & 770047.05 & -104160.047 & -98384.360 & 14 \\
Iranshahr & 1492847 & 1591231.36 & & & \\
& & & & &
\end{tabular}

Table 4. Estimation of efficiency scores by the Azadeh et al. (2007) algorithm

\begin{tabular}{cccccccc}
\hline Power Plants & $P_{\text {Real }(i)}$ & $P_{G P(i)}$ & $E_{i}$ & $E_{i}$ & $S h_{i}$ & $F i$ & Rank \\
\hline Montazerghaem & 3297100 & 3628549.66 & -331449.66 & -0.0913 & 1390450.97 & 65.69 & 12 \\
Besat & 1500253 & 2053443.7 & -553190.7 & -0.2694 & $786,874.38$ & 52.82 & 14 \\
Firoozi & 212403 & 782995.79 & -570592.79 & -0.7287 & $300,041.99$ & 19.61 & 19 \\
Salimi & $1.1 * 10^{7}$ & 8177297.48 & 3133519.52 & 0.3832 & 3133519.52 & 100 & 1 \\
Shazand & 7438002 & 7164642.93 & 273359.07 & 0.0382 & 2745472.89 & 75.05 & 6 \\
Rajaei & 6342203 & 5701384.48 & 640818.52 & 0.1124 & 2184755.98 & 80.42 & 4 \\
Beheshti & 1435991 & 1757228.32 & -321237.32 & -0.1828 & 673365.41 & 59.08 & 13 \\
Tabriz & 4341330 & 4617026.03 & -275696.03 & -0.0597 & 1769232.59 & 67.98 & 11 \\
Mofatteh & 5134547 & 5378608.18 & -244061.18 & -0.0454 & 2061068.93 & 69.02 & 10 \\
Bistoon & 4210280 & 4249969.03 & -39689.03 & -0.0093 & 1628577.29 & 71.62 & 8 \\
Ramin & $1.1 * 10^{7}$ & 9195861.73 & 1666005.27 & 0.1812 & 3523830.75 & 85.39 & 3 \\
Madhaj & 922587 & 1685681.91 & -763094.91 & -0.4527 & 645949.01 & 39.57 & 16
\end{tabular}




\begin{tabular}{cccccccc} 
Bandarabbas & 7196540 & 7340823.66 & -144283.66 & -0.0197 & 2812984.89 & 70.88 & 9 \\
Zarand & 341402 & 891289.53 & -549887.53 & -0.617 & 341539.87 & 27.69 & 18 \\
Esfahan & 5621431 & 5310960.15 & 310470.85 & 0.0585 & 2035146.38 & 76.52 & 5 \\
Montazeri & $1.1 * 10^{7}$ & 9370519.03 & 1766657.97 & 0.1885 & 3590758.98 & 85.93 & 2 \\
Toos & 3831065 & 3858784.97 & -27719.97 & -0.0072 & 1478676.55 & 71.78 & 7 \\
Mashhad & 665887 & 1245295.4 & -579408.4 & -0.4653 & 477194.02 & 38.66 & 17 \\
Iranshahr & 1492847 & 2043592.09 & -550745.09 & -0.2695 & 783099.28 & 52.81 & 15 \\
\hline
\end{tabular}

Table 5. Efficiency scores estimation based on the proposed approach

\begin{tabular}{cccccccc}
\hline Power Plants & $P_{\text {Real }}$ & $P_{G P}$ & $D_{i}$ & $E_{\text {Weight }(i)}$ & $R E_{\text {Score }(i)}$ & $E_{\text {score }(i)}$ & Rank \\
\hline Montazerghaem & 3297100 & 3335966.289 & 38866.28949 & 0.0113 & 0.98835 & 93.23 & 9 \\
Besat & 1500253 & 1682872.54 & 182619.5355 & 0.0531 & 0.89148 & 84.09 & 15 \\
Firoozi & 212403 & 310681.88 & 98278.88412 & 0.0286 & 0.68367 & 64.49 & 19 \\
Salimi & 11310817 & 11000250.67 & 310566.3283 & 0.0902 & 1.02823 & 96.99 & 4 \\
Shazand & 7438002 & 7128665.43 & 309336.573 & 0.0899 & 1.04339 & 98.42 & 3 \\
Rajaei & 6342203 & 5982403.61 & 359799.3877 & 0.1045 & 1.06014 & 100 & 1 \\
Beheshti & 1435991 & 1366089.86 & 69901.13884 & 0.0203 & 1.05117 & 99.15 & 2 \\
Tabriz & 4341330 & 4594212.58 & 252882.5752 & 0.0735 & 0.94496 & 89.14 & 13 \\
Mofatteh & 5134547 & 5314179.90 & 179632.9004 & 0.0522 & 0.9662 & 91.14 & 12 \\
Bistoon & 4210280 & 4095904.47 & 114375.5264 & 0.0332 & 1.02792 & 96.96 & 5 \\
Ramin & 10861867 & 10764449.95 & 97417.05159 & 0.0283 & 1.00905 & 95.18 & 6 \\
Madhaj & 922587 & 944762.00 & 22175.00268 & 0.0064 & 0.97653 & 92.11 & 11 \\
Bandarabbas & 7196540 & 8144942.68 & 948402.6831 & 0.2756 & 0.88356 & 83.34 & 16 \\
Zarand & 341402 & 407945.86 & 66543.85697 & 0.0193 & 0.83688 & 78.94 & 18 \\
Esfahan & 5621431 & 5600168.68 & 21262.32276 & 0.0062 & 1.0038 & 94.69 & 7 \\
Montazeri & 11137177 & 11283224.42 & 146047.4151 & 0.0424 & 0.98706 & 93.11 & 10 \\
Toos & 3831065 & 3851999.95 & 20934.94534 & 0.0061 & 0.99457 & 93.81 & 8 \\
Mashhad & 665887 & 770047.05 & 104160.0469 & 0.0303 & 0.86474 & 81.57 & 17 \\
Iranshahr & 1492847 & 1591231.36 & 98384.36003 & 0.0286 & 0.93817 & 88.49 & 14 \\
\hline
\end{tabular}

To compare results and check the accuracy of the proposed method, a non-parametric inference methodSpearman rank correlation test- is used. To be more specific for each Power Plant, the statistical significances of the difference between the ranking obtained by proposed methodology, conventional and Azadeh et al. (2007) algorithm are determined using Spearman's rank correlation test. Spearman test evaluates the similarity of the rankings of the different DMUs. In the Spearman test, to examine the null hypothesis a test statistic, $\mathrm{Z}$, is calculated using Equations (9) and (10) and compared with a pre-determined level of significance, $\alpha$ value. The null hypothesis is "The rankings of two methods are not similar". By considering level of significance $\alpha$ equal to 0.05 , critical $\mathrm{Z}$ value will be 1.645 . If the test statistic computed by Equation (10) exceeds 1.645 , the null hypothesis is rejected and we can conclude that alternate hypothesis which is "The two rankings are similar" is true (IC \&Yurdakul, 2010).

$$
\begin{gathered}
r_{s}=1-\left[\frac{6 \sum_{j=1}^{k}\left(d_{j}\right)^{2}}{K\left(K^{2}-1\right)}\right] \\
Z=r_{s} \sqrt{(K-1)}
\end{gathered}
$$


In Equation (9), $d_{j}$ is the ranking difference of Power Plants $j$ in different methods and $K$ is the number of Power Plants. $r_{s}$ represents the Spearman rank correlation coefficient. Table 6 shows the calculated values of $d_{j}$, $r_{s}$ and $\mathrm{Z}$.

Table 6. Determination of the significance of the difference between the proposed method and conventional methods

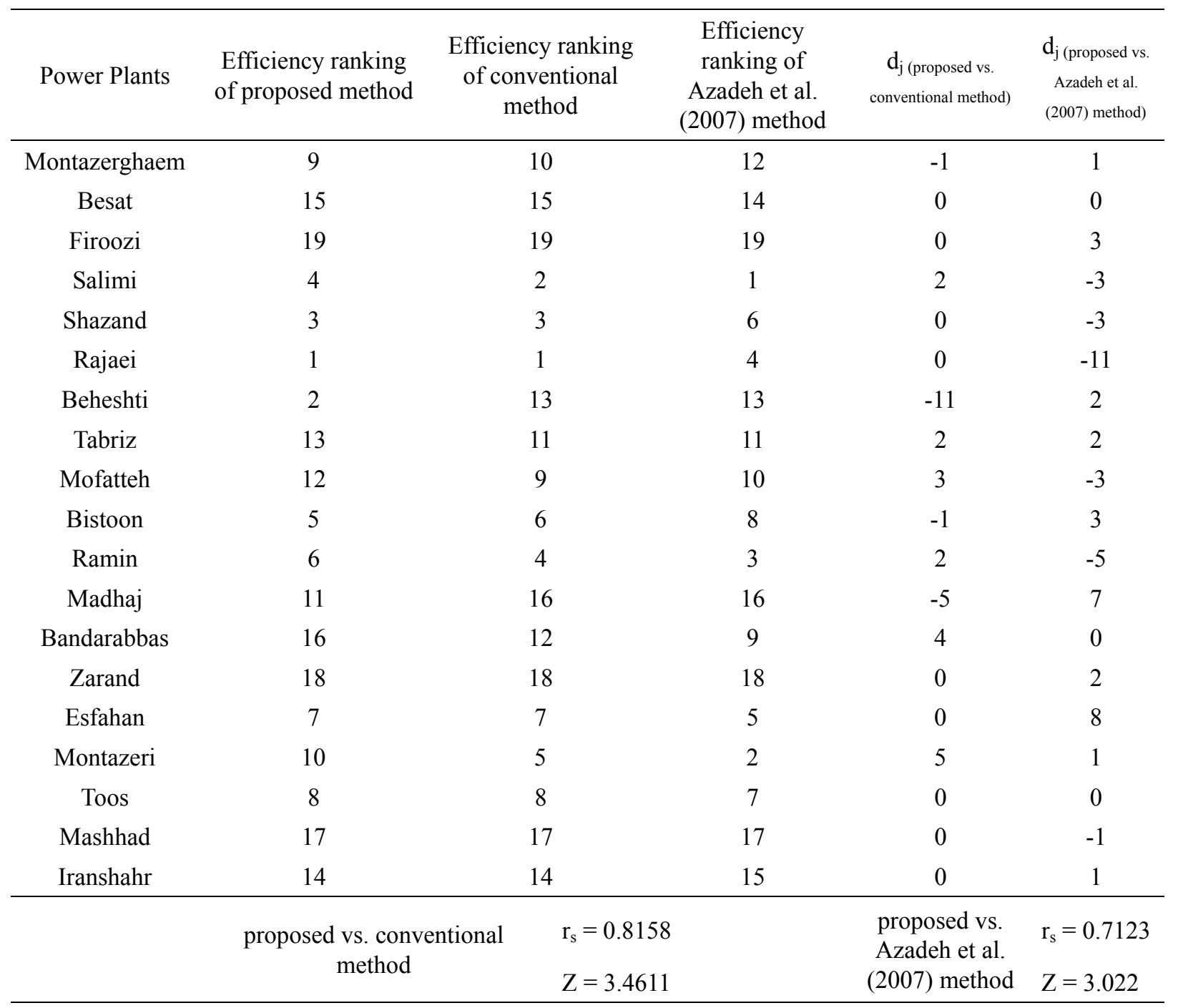

The calculated Z-values, 3.4611 and 3.022, are higher than 1.645, which indicates that the difference in ranking results of the proposed vs. conventional method and the proposed vs. Azadeh et al. (2007) method, by considering level of significance $\alpha$ equal to 0.05 is statistically insignificant. Based on the test results, it can be concluded that the ranking of Power Plants, obtained by proposed method is reliable.

Table 7 shows the summarized main results in presenting the efficiency scores of the conventional and proposed algorithm and PCA (ZPCA). Based on the results in Table 7, it can be seen that the mean efficiency scores of the conventional algorithm is smaller than mean technical efficiency for the Power Plants based on the proposed algorithm. Statistical t-test has been conducted In order to test significantly difference of the two technical efficiencies obtained from the two algorithms. 
Table 7. Efficiency scores results

\begin{tabular}{lcc}
\hline Power Plants & $\begin{array}{c}\text { Efficiency scores by the proposed } \\
\text { algorithm }\end{array}$ & $\begin{array}{c}\text { Efficiency scores by Azadeh et al. (2007) } \\
\text { algorithm }\end{array}$ \\
\hline Bandarabbas & 93.23 & 65.69 \\
Beheshti & 84.09 & 52.82 \\
Besat & 64.49 & 19.61 \\
Bistoon & 96.99 & 100 \\
Esfahan & 98.42 & 75.05 \\
Firoozi & 100 & 80.42 \\
Iranshahr & 99.15 & 59.08 \\
Madhaj & 89.14 & 67.98 \\
Mashhad & 91.14 & 69.02 \\
Mofatteh & 96.96 & 71.62 \\
Montazerghaem & 95.18 & 85.39 \\
Montazeri & 92.11 & 39.57 \\
Rajaei & 83.34 & 70.88 \\
Ramin & 78.94 & 27.69 \\
Salimi & 94.69 & 76.52 \\
Shazand & 93.11 & 85.93 \\
Tabriz & 93.81 & 71.78 \\
Toos & 81.57 & 38.66 \\
Zarand & 88.49 & 52.81 \\
Mean & 90.255 & 63.711 \\
\hline
\end{tabular}

The results of t-test are illustrated in Table 8 .

Table 8. Hypothesis testing of the mean efficiencies $(\boldsymbol{\mu} \mathrm{E})$ of the proposed and Azadeh et al. (2007) algorithms

\begin{tabular}{ll}
\hline Hypothesis & \\
\hline $\mathrm{H}_{0}$ & $\mu_{E}$ (proposed algorithm) $-\mu_{E}$ (Azadeh et al. $(2007)>25$ \\
$\mathrm{H}_{1}$ & $\mu_{E}$ (proposed algorithm) $-\mu_{E}$ (Azadeh et al. (2007) algorithm) $<25$ \\
Calculated t-statistic & 0.30 \\
P-Value & 0.616 \\
& Since the p-value is greater than $\alpha$-level $(0.01)$, there is no evidence to \\
Decision & Reject $\mathrm{H}_{0}$. \\
\hline
\end{tabular}

Base on Table 8 The null hypothesis cannot be rejected, that means technical efficiencies of the proposed algorithm is 25 percent larger than mean technical efficiencies of the Azadeh et al (2007) algorithm at the 1\% level of significance.

\section{Conclusion}

In this paper a nine-step algorithm was proposed to measure and rank the efficiency of electricity production units (Power Plants) in Iran. The unique feature of proposed algorithm is using the result of GP model to calculate efficiency. Using GP can help to better estimate the performance patterns of Power Plants. GP doesn't require explicit assumption about the function structure of the dependent (output) and independent (input) variables and this can lead to better estimation and results than conventional method such as regression or neural 
network. The proposed algorithm was applied to a set of steam power plants in 2004 . The efficiency results and rankings were compared with the two other methods, conventional and Azadeh et al. (2007) approach. To validate our proposed algorithm and ensure that the proposed algorithm calculates the efficiency scores statistically similar to conventional method the Spearman rank correlation test is used. The results indicate that the efficiency scores are closer to the ideal efficiency with considering the fact that the rankings of Power Plants statistically remain the same. Because of better performance patterns recognition of GP method, the proposed algorithm calculates more precise and realistic results than the conventional approach. When the production function is unknown, The GP based algorithm for measuring technical efficiency can lead to better results than other techniques.

Because of lack of both theoretical and empirical works in efficiency analysis more research in this field is needed. For the future studies, utilization of other prediction techniques such as neural network in combination of GP method to better pattern recognition of production function is advised. Also to obtain more realistic results and to reduce the estimation error of results considering more output and input indicators is useful.

\section{References}

Alavi, A. H., Gandomi, A. H., Sahab, M. G., \& Gandomi, M. (2010). Multi expression programming: a new approach to formulation of soil classification. Engineering with Computers, 26(2), 111-118. http://dx.doi.org/10.1007/s00366-009-0140-7

Athanassopoulos, A. D., \& Curram, S. P. (1996). A comparison of data envelopment analysis and artificial neural networks as tools for assessing the efficiency of decision making units. Journal of the Operational Research Society, 1000-1016.

Azadeh, A., Ghaderi, S. F., Anvari, M., \& Saberi, M. (2007). Performance assessment of electric power generations using an adaptive neural network algorithm. Energy Policy, 35(6), 3155-3166. http://dx.doi.org/10.1016/j.enpol.2006.11.012

Azadeh, A., Ghaderi, S. F., Omrani, H., \& Eivazy, H. (2009). An integrated DEA-COLS-SFA algorithm for optimization and policy making of electricity distribution units. Energy Policy, 37(7), 2605-2618. http://dx.doi.org/10.1016/j.enpol.2009.02.021

Azadeh, A., Saberi, M., \& Anvari, M. (2010). An integrated artificial neural network algorithm for performance assessment and optimization of decision making units. Expert Systems with Applications, 37(8), 5688-5697. http://dx.doi.org/10.1016/j.eswa.2010.02.041

Azamathulla, H. M., \& Ghani, A. A. (2010). Genetic programming to predict river pipeline scour. Journal of $\begin{array}{lllll}\text { Pipeline Systems Engineering and } & \text { 127-132. }\end{array}$ http://dx.doi.org/10.1061/(ASCE)PS.1949-1204.0000060

Azamathulla, H. M., \& Ghani, A. A. (2011). Genetic programming for predicting longitudinal dispersion coefficients in streams. Water Resources Management, 25(6), 1537-1544. http://dx.doi.org/10.1007/s11269-010-9759-9

Azamathulla, H. M., AB GHANI, A., Zakaria, N. A., Lai, S. H., Chang, C. K., Leow, C. S., \& Abuhasan, Z. (2008). Genetic programming to predict ski-jump bucket spill-way scour. Journal of Hydrodynamics, Ser. B, 20(4), 477-484. http://dx.doi.org/10.1016/S1001-6058(08)60083-9

Bauer, P. W. (1990). Recent developments in the econometric estimation of frontiers. Journal of econometrics, 46(1-2), 39-56. http://dx.doi.org/10.1016/0304-4076(90)90046-V

Bauer, P. W., Berger, A. N., Ferrier, G. D., \& Humphrey, D. B. (1998). Consistency conditions for regulatory analysis of financial institutions: a comparison of frontier efficiency methods. Journal of Economics and Business, 50(2), 85-114. http://dx.doi.org/10.1016/S0148-6195(97)00072-6

Brezocnik, M., \& Balic, J. (2001). A genetic-based approach to simulation of self-organizing assembly. Robotics $\begin{array}{llll}\text { and } \quad \text { Computer-Integrated } \quad \text { Manufacturing, } & \text { 17(1-2), }\end{array}$ http://dx.doi.org/10.1016/S0736-5845(00)00044-2

Çelebi, D., \& Bayraktar, D. (2008). An integrated neural network and data envelopment analysis for supplier evaluation under incomplete information. Expert Systems with Applications, 35(4), 1698-1710. http://dx.doi.org/10.1016/j.eswa.2007.08.107

Costa, A., \& Markellos, R. N. (1997). Evaluating public transport efficiency with neural network models. Transportation Research Part C: Emerging Technologies, 5(5), 301-312. 
http://dx.doi.org/10.1016/S0968-090X(97)00017-X

Delgado, F. J. (2005). Measuring efficiency with neural networks. An application to the public sector. Economics Bulletin, 3(15), 1-10.

EIA. (n.d.). Energy Information Administration - Official Energy Statistics from the U.S. Government. Retrieved from http://www.eia.doe.gov/

Emami, M. A. (1998). Efficiency considerations in the electricity supply industry: the case of Iran. A thesis submitted to university of Surrey for the degree of Doctor of Philosophy.

Fare, R., Grosskopf, S., \& Lovell, C. A. K. (1985). The measurement of efficiency of production. Springer. http://dx.doi.org/10.1007/978-94-015-7721-2

Gandomi, A.H., Alavi, A.H., Arjmandi, P., Vesali, M. (2010). Modeling of Compressive Strength of HPCMixes Using a Combined Algorithm of Genetic Programming and Orthogonal Least Squares. Journal of Mechanics of Materials and Structures, in press. http://dx.doi.org/10.2140/jomms.2010.5.735

Hawdon, D. (1998). Improving the performance of electricity industries in developing countries: Is World Bank policy on deregulation the way forward. Deregulation of Electric Utilities, 203-27. http://dx.doi.org/10.1007/978-1-4615-5729-6_9

Iba, H., \& Sasaki, T. (2002). Using genetic programming to predict financial data. Evolutionary Computation, 1999. CEC 99. Proceedings of the 1999 Congress on (Vol. 1).

IC, Y. T., \& Yurdakul, M. (2010). Development of a quick credibility scoring decision support system using fuzzy TOPSIS. Expert Systems with Applications, 37(1), 567-574. http://dx.doi.org/10.1016/j.eswa.2009.05.038

Iglesias, G., Castellanos, P., \& Seijas, A. (2010). Measurement of productive efficiency with frontier methods: A case study for wind farms. Energy Economics, 32(5), 1199-1208. http://dx.doi.org/10.1016/j.eneco.2010.03.004

Jamasb, T., \& Pollitt, M. G. (2004). Benchmarking and regulation of electricity transmission and distribution utilities: lessons from international experience.

Kaboudan, M. A. (2000). Genetic programming prediction of stock prices. Computational Economics, 16(3), 207-236. http://dx.doi.org/10.1023/A:1008768404046

Kaboudan, M. A. (2003). Forecasting with computer-evolved model specifications: a genetic programming application. Computers \& Operations Research, 30(11), 1661-1681. http://dx.doi.org/10.1016/S0305-0548(02)00098-9

Karabulut, K., Alkan, A., \& Yilmaz, A. S. (2008). Long term energy consumption forecasting using genetic programming. Mathematical and Computational Applications, 13(2), 71.

Khu, S. T., Liong, S. Y., Babovic, V., Madsen, H., \& Muttil, N. (2001). Genetic Programming and Its Application in Real-Time Runoff Forecasting. Journal of the American Water Resources Association, 37(2), 439-451. http://dx.doi.org/10.1111/j.1752-1688.2001.tb00980.x

Kovacic, M., Balic, J., \& Brezocnik, M. (2004). Evolutionary approach for cutting forces prediction in milling. Journal of Materials Processing Technology, 155-156, 1647-1652. http://dx.doi.org/10.1016/j.jmatprotec.2004.04.318

Koza, J. R. (1992). Genetic programming: on the programming of computers by means of natural selection. The MIT press.

Lee, D. G., Lee, B. W., \& Chang, S. H. (1997). Genetic programming model for long-term forecasting of electric

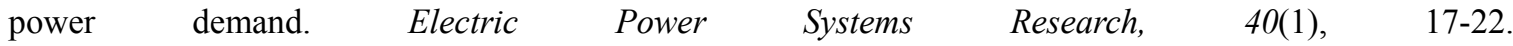
http://dx.doi.org/10.1016/S0378-7796(96)01125-X

Li, W. X., Dai, L. F., Hou, X. B., \& Lei, W. (2007). Fuzzy genetic programming method for analysis of ground movements due to underground mining. International Journal of Rock Mechanics and Mining Sciences, 44(6), 954-961. http://dx.doi.org/10.1016/j.ijrmms.2007.02.003

Liu, C. H., Lin, S. J., \& Lewis, C. (2010). Evaluation of thermal power plant operational performance in Taiwan by data envelopment analysis. Energy Policy, 38(2), 1049-1058. http://dx.doi.org/10.1016/j.enpol.2009.10.057

Mostafa, M. M. (2009). Modeling the efficiency of top Arab banks: A DEA-neural network approach. Expert 
Systems with Applications, 36(1), 309-320. http://dx.doi.org/10.1016/j.eswa.2007.09.001

Muttil, N., \& Lee, J. H. W. (2005). Genetic programming for analysis and real-time prediction of coastal algal blooms. Ecological Modelling, 189(3-4), 363-376. http://dx.doi.org/10.1016/j.ecolmodel.2005.03.018

Park, S. U., \& Lesourd, J. B. (2000). The efficiency of conventional fuel power plants in South Korea: A comparison of parametric and non-parametric approaches. International Journal of Production Economics, 63(1), 59-67. http://dx.doi.org/10.1016/S0925-5273(98)00252-7

Pendharkar, P. C. (2011). A hybrid radial basis function and data envelopment analysis neural network for classification. Computers \& Operations Research, 38(1), 256-266. http://dx.doi.org/10.1016/j.cor.2010.05.001

Pérez-Reyes, R., \& Tovar, B. (2010). Explaining the inefficiency of electrical distribution companies: Peruvian firms. Energy Economics, 32(5), 1175-1181. http://dx.doi.org/10.1016/j.eneco.2010.02.002

Pombo, C., \& Taborda, R. (2006). Performance and efficiency in Colombia's power distribution system: Effects of the 1994 reform. Energy Economics, 28(3), 339-369. http://dx.doi.org/10.1016/j.eneco.2005.08.001

Silva, S. (2007). GPLAB, a genetic programming toolbox for MATLAB. Retrieved from http://gplab.sourceforge.net

Sueyoshi, T., \& Goto, M. (2001). Slack-adjusted DEA for time series analysis: Performance measurement of Japanese electric power generation industry in 1984-1993. European Journal of Operational Research, 133(2), 232-259. http://dx.doi.org/10.1016/S0377-2217(00)00295-2

Sueyoshi, T., Goto, M., \& Ueno, T. (2010). Performance analysis of US coal-fired power plants by measuring three DEA efficiencies. Energy Policy, 38(4), 1675-1688. http://dx.doi.org/10.1016/j.enpol.2009.11.017

Sun, R., Tsung, F., \& Qu, L. (2004). Combining bootstrap and genetic programming for feature discovery in diesel engine diagnosis. International Journal of Industrial Engineering, 11(3), 273-281.

TAVANIR management organization, 1997-2004. Electric Power Industryin Iran 1997-2004, TAVANIR management organization. Retrieved from http://www.tavanir.org.ir

Tsakonas, A. (2006). A comparison of classification accuracy of four genetic programming-evolved intelligent structures. Information Sciences, 176(6), 691-724. http://dx.doi.org/10.1016/j.ins.2005.03.012

Tyagi, P., Yadav, S. P., \& Singh, S., 2009. Relative performance of academic departments using DEA with sensitivity analysis. Evaluation and Program Planning, 32(2), 168-177. http://dx.doi.org/10.1016/j.evalprogplan.2008.10.002

Wang, C. H., Chuang, C. C., \& Tsai, C. C. (2009). A fuzzy DEA-Neural approach to measuring design service performance in PCM projects. Automation in Construction, 18(5), 702-713. http://dx.doi.org/10.1016/j.autcon.2009.02.005

Willis, M. J., Hiden, H. G., McKay, B., Montague, G. A., \& Marenbach, P. (1997). Genetic programming: An introduction and survey of applications. IEE Conference Publications (pp. 314-319).

Wu, D. (2009). Supplier selection: A hybrid model using DEA, decision tree and neural network. Expert Systems with Applications, 36(5), 9105-9112. http://dx.doi.org/10.1016/j.eswa.2008.12.039

Wu, D. D., Yang, Z., \& Liang, L. (2006). Using DEA-neural network approach to evaluate branch efficiency of a large Canadian bank. Expert Systems with Applications, 31(1), 108-115. http://dx.doi.org/10.1016/j.eswa.2005.09.034

Yunos, J. M., \& Hawdon, D. (1997). The efficiency of the national electricity board in Malaysia: An intercountry $\begin{array}{llll}\text { comparison using DEA. Energy } & \text { Economics, }\end{array}$ http://dx.doi.org/10.1016/S0140-9883(96)01018-3

\section{Copyrights}

Copyright for this article is retained by the author(s), with first publication rights granted to the journal.

This is an open-access article distributed under the terms and conditions of the Creative Commons Attribution license (http://creativecommons.org/licenses/by/3.0/). 